\title{
A EDUCAÇÃO NA ALEMANHA DURANTE O TERCEIRO REICH E SEU PAPEL NA DOUTRINAÇÃO DAS CRIANÇAS E JOVENS
}

\author{
EDUCATION IN GERMANY DURING THE THIRD REICH AND ITS ROLE IN THE \\ INDOCTRINATION OF CHILDREN AND YOUNG PEOPLE
}

Gabriele Alves Vicente', Marcos Antônio Witt²

\author{
Recebido em: 25 de abril de 2017 \\ Aprovado em: 15 de setembro de 2017 \\ Sistema de Avaliação: Double Blind Review \\ RCO | a. 10 | v. 1 | p. 71-87 | jan./jun. 2018 \\ DOI: https://doi.org/10.25112/rco.v1i0.1179
}

\begin{abstract}
RESUMO
O presente trabalho analisa as modificações instauradas no sistema educacional alemão regular e extracurricular durante o período correspondente ao Terceiro Reich (1933-1945) e sua influência na formação das crianças e jovens. O objetivo constitui-se em ressaltar a educação escolar como um dos meios utilizados pelo partido nazista para propagar sua ideologia sobre a juventude, destacando as transformações ocorridas dentro do currículo escolar regular. E, ainda, o empenho por parte do partido no que diz respeito ao incentivo da continuidade dos ensinos ideológicos nazistas em atividades extracurriculares como a Organização denominada Juventude Hitlerista, em alemão - Hitlerjugend. Essa Organização visava aprofundar ainda mais na mente dos jovens todas as ideias centrais do nazismo com o intuito de que essa geração mais nova se submetesse fielmente ao seu Führer. A metodologia empregada para a realização desta análise baseou-se principalmente em duas obras, que são: Juventude Hitlerista: mocidade traída, lançado em 1973 por H. W Koch e Juventude Hitlerista: a história dos meninos e meninas nazistas e daqueles que resistiram, publicado em 2006, por Susan Campbell Bartoletti. Com essa análise, torna-se possível compreender, na medida do possível, o por que naquele momento específico, grande parte da juventude alemã aceitou e apoiou a construção da identidade da nação almejada e idealizada por Adolf Hitler e o nacional-socialismo.
\end{abstract}

Palavras-chave: Nazismo. Educação. Doutrinação. Juventude Hitlerista.

\begin{abstract}
The present work analyzes the changes established in the German regular and extracurricular educational system during the period corresponding to the Third Reich (1933-1945) and its influence on the education of children and young people. The objective is to emphasize school education as one of the means used by the Nazi party to propagate its ideology under youth, highlighting the transformations which had occurred within the regular school curriculum. And its commitment to ensure continuity in the Nazi ideological teachings in extracurricular activities like the Organization called Hitler Youth, in German - Hitlerjugend. This organization aimed to intensify in the minds of young people all the central ideas of Nazismin order that younger generation would submit faithfully to their Führer. The methodology employed to carry out this analysis was based mainly on two works, which are: Hitler Youth: Betrayed youth, launched in 1973 by H. W Koch and Hitler Youth: the story of Nazi boys and girls and those who resisted, published In 2006, by Susan Campbell Bartoletti. Thus, through this analysis, it is possible to understand, up to a certain point, the reasons why at that particular time, most
\end{abstract}

\footnotetext{
${ }^{1}$ Graduada em História pela Universidade do Vale do Rio dos Sinos (São Leopoldo/Brasil). E-mail: gabrieleavicente@ gmail.com.

${ }_{2}^{2}$ Doutor em História pela Pontifícia Universidade Católica do Rio Grande do Sul (Porto Alegre/Brasil). Professor na Universidade do Vale do Rio dos Sinos (São Leopoldo/Brasil). E-mail: mawitt@unisinos.br.
} 
part of the German youth accepted and supported the construction of the nation identity sought and idealized by Adolf Hitler and National Socialism.

Keywords: Nazism. Education. Indoctrination. Hitler Youth.

\section{INTRODUÇÃO}

Este artigo tem como objetivo apresentar uma análise sobre como Hitler $^{3}$ e o governo nazista obtiveram tanta influência sobre o povo alemão, mais especificadamente sobre os jovens, convencendo grande parte daquela geração a serem devotos ao líder nazista e à sua ideologia racista de mundo.

Hoje facilmente se consegue discernir e identificar que a doutrina apregoada pelo nazismo não tem fundamento científico, como defendia Hitler, mas é sim uma concepção racista que desencadeou na Alemanha um regime tirânico com todos os prejuízos já identificados. A atuação de Hitler enquanto esteve no poder foi caracterizada como totalitária, segundo alguns autores como Hanna Arendt ${ }^{4}$. Conforme Arendt (1989) existe a utopia política de que para começar um novo mundo é natural investir nos mais jovens de uma sociedade e que com isso muitos dos regimes tirânicos ao chegarem no poder focalizaram na doutrinação das crianças e jovens, pois esses absorviam mais facilmente as novas ideologias.

Durante o governo do Terceiro Reich (1933-1945), pode-se destacar um grande crescimento na valorização dada às crianças e jovens da nação alemã objetivando atrair esses para o movimento nazista, podendo assim aproveitar o seu potencial em prol do nacional-socialismo.

Sendo assim é possível observar que as crianças e jovens do Terceiro Reich foram submetidas a um programa dogmático que não lhes apresentou opção alternativa segura de escolha, e é sobre essa dogmática que tratarei neste estudo. Logicamente não é possível dar uma única resposta simples e fechada a essa questão, pois foram muitos fatores que levaram a juventude a seguir o líder nazista, mas procura-se trazer uma breve análise sobre o tema.

Para a realização deste artigo foram utilizadas duas obras principais para a pesquisa. A primeira são os relatos de H. W Koch, alemão que vivenciou o período da guerra como membro da Juventude Hitlerista (Organização de jovens alemães) e uma das muitas vítimas do sistema imposto às crianças e jovens. Koch lutou pelo Führer ${ }^{5}$ em quem acreditava até o momento em que, como apresenta S. L Mayer "a máscara do nazismo foi arrancada" (KOCH, 1973, p. 7). Koch posteriormente tornou-se Conferencista de História da Alemanha na Universidade de York e reuniu não apenas suas lembranças, mas também uma análise sobre os acontecimentos em si, reunindo tudo no livro - Juventude Hitlerista: mocidade traída, lançado em 1973, do qual foi utilizado neste trabalho. A segunda obra consultada foi o livro de Susan Campbell Bartoletti, autora que entrevistou sobreviventes da Segunda Guerra que compartilharam suas vivências, inclusive no âmbito educacional. Entre os entrevistados pela autora

\footnotetext{
${ }^{3}$ Adolf Hitler (1889-1945) foi um político alemão, líder do Partido Nacional-Socialista dos Trabalhadores Alemães (Partido Nazista). Ao ser nomeado Chanceler em 1933 começou a aplicar o programa nazista e numa sucessão de golpes, atos ilegais e assassinatos instalou sua ditadura. Com a morte do presidente alemão Paul Von Hindenburg, Hitler acumulou a função de chanceler e presidente dando início do Terceiro Reich (1934 - 1945). Historicamente é considerado o principal responsável por dar início a Segunda Guerra Mundial, conflito global que durou de 1939 a 1945, mas que perpetua suas marcas até hoje (PERRY, 1985).

${ }^{4}$ Hanna Arendt vivenciou as duas Guerras Mundiais e como judia foi perseguida na Segunda Guerra conseguindo fugir para os Estados Unidos onde permaneceu até sua morte em 1975. Estudou os regimes autoritários (totalitários) instaurados ao longo do século XX - nazismo e comunismo - tornando-se reconhecida principalmente pela obra As origens do totalitarismo, livro que trata sobre esta questão (PERRONE-MOISÉS, 2013).

5 Führer em alemão, o "condutor", "guia", "líder" ou "chefe". Embora a palavra permaneça comum no alemão, está tradicionalmente associado a Adolf Hitler, que a usou para se designar líder da Alemanha Nazista.
} 
encontram-se membros da Juventude Hitlerista, judeus, vítimas do período e outros alemães que não aderiram ao nazismo. A autora reúne esses relatos em sua obra - Juventude Hitlerista: a história dos meninos e meninas nazistas e a dos que resistiram, na obra lançada em 2006. O livro é uma excelente obra para analisar as transformações realizadas nas escolas e nas atividades impostas aos jovens. Explorou-se também outras referências bibliográficas que complementaram a análise proposta.

\section{MODIFICAÇÃO NO CURRÍCULO ESCOLAR REGULAR E ATIVIDADES EXTRACURRICULARES}

$\mathrm{O}$ ambiente escolar constituiu-se em um local apropriado para influenciar o pensamento das crianças e jovens alemãs. Sendo assim, a escola regular passou a desempenhar o papel de condutor do pensamento nazista e mais do que isso passou a exigir a uniformidade intelectual no que diz respeito à ideologia propagada pelo Partido.

A proposta da modificação no sistema educacional foi sem dúvida uma das primeiras ações a serem tomadas pelo Terceiro Reich. A escola se destaca então como o local apropriado para dar início a essa transformação na mentalidade dos mais jovens. De fato, o partido conseguiu colocar em prática sua estratégia, pois primeiramente instituiu a nazificação de todas as escolas regulares existentes, implantando a ideologia do programa nazista resumida em:

O trabalho de educação coletiva do Estado nacionalista deve ser coroado com o despertar do sentido e do sentimento da raça, que deve penetrar no coração e no cérebro da juventude que lhe foi confiada. Nenhum rapaz, nenhuma rapariga deve abandonar a escola sem estar convencido da necessidade de manter a pureza da raça (HITLER, 2001, p. 322).

Essa ideia de modificação do sistema escolar foi proposta por Hitler em sua obra Mein $\operatorname{Kempf}^{6}$ e colocada em prática quando ele alcançou o poder:

\footnotetext{
Em primeiro lugar, o cérebro infantil não deve ser sobrecarregado com assuntos, noventa por cento dos quais são desnecessários e cedo esquecidos [...]. Em muitos casos a matéria é tão vasta que só uma parte é conservada e essa mesmo não encontra emprego na vida prática. Do outro lado, nada se aprende que seja de utilidade, em uma determinada profissão, para a conquista do pão cotidiano (HITLER, 2001, p. 316).
}

Para Hitler não era útil o ensino de diversos conhecimentos, pois as crianças e os jovens não os absorviam totalmente, deixando-os sobrecarregados de conteúdos, porém sem a compreensão dos mesmos. Nesse aspecto, Hitler critica o ensino de diversas línguas no currículo, como, por exemplo, o francês, que para a maioria não teria serventia nenhuma em sua vida posterior à escola. Sua intenção era ensinar aos alunos apenas as coisas que serviriam para seu futuro de maneira prática, ou seja, conhecimentos que fossem usar em suas profissões e que estivessem conectados com a maior preocupação dele, o futuro da nação alemã com jovens úteis para a sociedade. Com a retirada dessas línguas consideradas inúteis, sobraria mais tempo para outras disciplinas mais importantes.

Sendo assim, pode-se destacar que a finalidade da educação para o líder Alemão e o partido nazista consistia em "transformar as crianças em bons nazistas" (BARTOLETTI, 2006, p. 40). Na busca por corresponder ao desejo de Hitler, tornava-se essencial, tanto para os alunos quanto para os professores, professar a fé que tinham no sistema racista apresentado por Hitler, auxiliando na luta pela

\footnotetext{
${ }^{6}$ Mein Kempf traduzido para o português como Minha Luta foi a obra iniciada por Adolf Hitler enquanto este encontrava-se no presídio militar de Ladsberg na Baviera, antes de governar a Alemanha. Trata-se se um livro que carrega a ideologia nazista que serviu como base para a atuação do nacional-socialismo (PERRY, 1985).
} 
nova Alemanha que deveria ser pura e sem os inimigos da raça ariana. Nisso cada aluno era encorajado a vigiar, assim como também era vigiado, para estar de acordo com os pressupostos nazistas.

Além das escolas públicas terem sido nazificadas durante o governo do Terceiro Reich, também foram criadas escolas diferenciadas para o propósito de a doutrinação ser ainda mais profunda. Conforme Evans (2011, p. 370):

No aniversário de Hitler, em 20 de abril de 1933, Rust fundou três instituições políticoeducacionais nacionais, ou 'Napolas', internatos montados nos prédios das antigas escolas de cadetes da Prússia (extintas pelo Tratado de Versalhes) e planejados para treinar uma nova elite para governar o futuro Terceiro Reich.

Além das Napolas foram criadas também as chamadas Escolas Adolf Hitler. Conforme Evans (2011, p. 374):

\begin{abstract}
Em 15 de janeiro de 1937, o líder da Juventude do Reich, Baldur von Schirach, e o líder da Frente de Trabalho Alemã, Robert Ley, emitiram um anúncio conjunto informando que Hitler, por solicitação deles, havia dado ordem para a fundação das 'Escolas Adolf Hitler', colégios secundários dirigidos pela Juventude Hitlerista, que determinaria o currículo, com supervisão dos líderes regionais do Partido Nazista.
\end{abstract}

Essas novas instituições eram destinadas a alunos específicos, que teriam potencial de formar a nova elite alemã. Sendo assim, para ingressarem tanto nas Napolas, quanto nas Escolas Adolf Hitler, era necessário demonstrar algumas aptidões específicas, conforme Bartoletti (2006).

Portanto, pode-se observar que as crianças estavam envolvidas por todos os lados da doutrinação nazista, seja para os estudantes de escolas regulares ou ainda os integrantes das novas instituições mais direcionadas a um perfil específico de alemão. Com isso, todas as crianças eram submetidas a um rigoroso programa que contemplava os ideais nazistas para que fossem moldados neles desde cedo. $\mathrm{O}$ programa didático-pedagógico nazista foi vinculado totalmente em conformidade com a visão de mundo defendida pelo nacional-socialismo. Para Hitler, a escola era o ambiente ideal para cumprir seu propósito. Destaca Bartoletti (2006, p. 45): "Hitler concordava que o sistema educacional dele era duro, mas fundamental para sua meta. - Eu busco uma juventude profundamente ativa, dominadora, brutal disse. - A juventude deve ser indiferente à dor. Não pode ter fraqueza, nem carinho".

Para por em prática esta ideia de transformação dos jovens em bons nazistas através da educação escolar, muitas modificações foram feitas atendendo a ideologia proposta por Hitler: "Assim que os nazistas assumiram o poder, passaram a controlar as escolas públicas, chamada Escolas Nacionais. Jogaram fora os livros e lançaram novos. Mudaram os currículos de alto a baixo, de forma a só ensinar ideias aprovadas pelo nazismo" (BARTOLETTI, 2006, p. 40).

As mudanças foram bastante significativas no que diz respeito às matérias ensinadas na escola. Disciplinas que aparentemente não poderiam exercer influência no pensamento ideológico de um jovem foram também submetidas a transformações visando o reforço da apreciação pelo nazismo. Observamse algumas dessas modificações a seguir.

\title{
2.1 EDUCAÇÃO FÍSICA
}

Começando pela disciplina da Educação física, que para Hitler representava a mais importante matéria a ser desenvolvida, para ele a educação deveria visar o aperfeiçoamento físico do indivíduo: 
Tendo isso em vista, o Estado deve dirigir a educação do povo, não no sentido puramente intelectual, mas visando sobretudo à formação de corpos sadios. Em segundo plano, é que vem a educação intelectual. Aqui, ainda, a formação do caráter deve ser a primeira preocupação, especialmente a formação do poder de vontade e de decisão e o hábito de assumir com prazer todas as responsabilidades (HITLER, 2001, p. 309).

Devido às isso, as aulas de Educação Física passaram a representar uma das matérias mais importantes. A principal intenção do Estado deveria ser a formação de jovens saudáveis fisicamente, com um caráter fortalecido (conforme os padrões nazistas) e que com isso pudessem dar ao mundo novos seres tão qualificados quanto eles através da procriação.

Hitler culpa em parte a educação ensinada à juventude antes de sua subida ao poder, pela derrota anterior da Alemanha na Primeira Guerra Mundial. Segundo ele, se os cidadãos tivessem aprendido lutas como o boxe e fortalecido seu físico através da prática esportiva e não focando tanto no aprendizado intelectual, os resultados teriam sido diferentes. "Se nossa juventude, nas escolas, tivesse aprendido menos conhecimentos e se tivesse mais exercitado no domínio de si mesma, grandes vantagens se teriam verificado nos anos de 1915 - 1918" (HITLER, 2001, p. 315).

Desse modo, o programa do nacional-socialismo busca focar nesses pontos antes não levados tão em consideração, de acordo com ele. A preocupação com o caráter é num sentido de impulso na afirmação da superioridade que cada ariano deveria sentir sobre si e sobre sua nação, pois através disso desenvolveria um espírito forte que não poderia ser vencido. Destaca Hitler (2001, p. 15) que "Por tudo isso, o Estado nacionalista, na sua missão educativa, deve dar a maior importância à Educação Física e à do caráter." E ainda:

Essa confiança deve ser cultivada na juventude, desde a meninice. Toda a sua educação, todo o seu treinamento, devem ser dirigidos no sentido de dar-lhe a convicção da sua superioridade. Certa da sua força e da sua habilidade, a mocidade deve readquirir a fé na invencibilidade da sua nação (HITLER, 2001, p. 312).

O treinamento das aptidões corporais ganhou então grande espaço na escola. Segundo Bleuel (1972, p. 158) "as escolas passaram daí em diante a dedicar de três a cinco horas semanalmente às suas aulas de ginástica." Destaca-se ainda o treinamento do boxe que foi incorporado ao currículo escolar.

As meninas também recebiam instrução corporal para tornarem-se aptas a sua tarefa de mães da nova geração. Destaca Bleuel (1972, p. 177): "Para a futura mãe da nação faz-se mister, imprescindível desde já, instituir um sadio sistema de educação corporal para a mocinha. $\mathrm{O}$ excessivo acúmulo de conhecimentos teóricos deve ser evitado em benefício do pleno conhecimento físico da adolescente".

Sendo assim, a importância dada ao trabalho da educação física e também ao da ginástica era muito grande, pois proporcionava o aprimoramento do corpo essencial para os propósitos nazistas.

\subsection{HISTÓRIA E GEOGRAFIA}

A disciplina de história teve seu conteúdo totalmente modificado como se vê nos relatos de Koch (1973, p. 98):

A História também foi matéria seriamente atingida. Todos os livros da disciplina foram submetidos a rigorosa revisão. O primeiro compêndio de história que este autor recebeu num ginásio, em 1943, começava com Adolf Hitler e acabava com Anibal. A história era exclusivamente político-militar, focalizando a luta contínua do povo alemão pelo poder e pela existência.

De acordo com Evans (2011, p. 348): 
Em 30 de julho de 1933 um decreto central dispôs as 'Diretrizes para Livros Didáticos de História', segundo as quais as aulas de história dali em diante deveriam ser montadas em torno do 'conceito de heroísmo em sua forma alemã, ligado à ideia de liderança'. Em breve os estudantes estavam às voltas com redações sobre tópicos como 'Hitler: o realizador da unidade alemã', 'a revolução nacionalista como o começo de uma nova era'.

Estudar a história serviria não para entender o passado, mas para orientar o futuro da nação alemã. A intenção aqui era reformular a história do mundo tornando a questão racial o ponto dominante nos acontecimentos.

\begin{abstract}
O Estado nacionalista deve ver na ciência um meio de aumentar o orgulho nacional. Tanto a história universal quanto a história da civilização devem ser ensinadas sob esse aspecto. Um inventor deve ser visto não só por que é inventor, mas também porque é um dos nossos compatriotas. A admiração por todas as grandes ações deve ser combinada ao orgulho por ser seu executor um membro da nossa pátria. Devemos selecionar as maiores figuras da massa dos grandes nomes da nossa história e pô-las diante da juventude de modo tão impressionante que elas possam servir de colunas mestras de um inabalável sentimento nacionalista (HITLER, 2001, p.321).
\end{abstract}

Tornou-se imprescindível ensinar apenas sobre figuras germânicas puras, deixando de lado todos os outros que não fossem alemães de sangue puro. Ou seja, a história passou a ser ensinada de um ponto de vista categórico, levando em conta apenas as ações de arianos, rejeitando todas as demais contribuições para a compreensão do mundo em si.

Destaca também Bleuel (1972), que o ensino histórico destinado aos alunos deveria sempre focar no conteúdo da revolução nacional, que apresentava Hitler como o Salvador da Alemanha. E não apenas isso, mas, como já mencionado, a história deveria estar focalizada sob o ponto de vista da raça nórdica, exaltando os feitos dos líderes alemães.

Nesta intenção de enaltecer as lideranças germânicas, Evans (2011, p. 349) traz um exemplo muito interessante da resposta que uma criança deu a uma pergunta dada como exercício em aula sobre o assunto:

\footnotetext{
Outra criança, ao receber a pergunta 'Nossos antepassados germânicos eram bárbaros?', soube imediatamente como traçar um paralelo com o passado recente: 'A alegação de que nossos antepassados germânicos eram bárbaros', escreveu ele, 'é mentira, igual, por exemplo, à mentira de que a Alemanha é a única culpada pela guerra mundial. Está provado que as tribos germânicas mantinham um alto nível cultural mesmo na Idade da Pedra',
}

Complementa ainda Evans (2011) que nas aulas de história os temas deveriam incluir ensinamentos sobre coragem na batalha, bem como reforçar a ideia de sacrifício por uma causa maior, deveriam aprender também sobre a total devoção ao líder Supremo da Alemanha e, ainda, sobre o ódio desmedido pelos judeus. Resume: "O objetivo da história era ensinar as pessoas que a vida sempre era dominada pela luta, que raça e sangue eram centrais em todos os acontecimentos do passado, presente e futuro, e que a liderança determinava o destino dos povos" (EVANS, 2011, p. 350).

A disciplina de Geografia também foi bastante modificada. Segundo as lembranças registradas de Koch (1973, p. 99): “A Geografia devia ser ensinada em termos de geopolítica, espaço vital, movimento demográfico, expansão racial e aquisição de territórios coloniais."

Esta disciplina foi então direcionada para atender a ideologia nazista, trazendo conceitos como os mencionados por Evans (2011) de lar, raça e heroísmo e os professores eram instruídos a estudar o Oriente, pois essa seria uma boa maneira de iniciar o assunto sobre os judeus. Ressalta Evans (2011, p. 352): 
Inúmeros livros didáticos de geografia propagaram conceitos como espaço vital e sangue e solo, e difundiram o mito da superioridade racial alemã. Os mapas mundiais e os novos livros didáticos enfatizaram a importância da geopolítica, corroboraram implicitamente o conceito de 'um povo, um Reich', ou traçaram a expansão das tribos germânicas através da Europa do leste e central na Idade Média.

Bleuel (1972) destaca também que nas aulas de Geografia os professores prosseguiam em uma preparação do espírito dos alunos baseadas nas teorias sobre raça juntamente com a geopolítica, a fim de abrir espaço para os ideais de expansão política ambicionados por Hitler.

A fotografia a seguir mostra uma turma de meninos na aula de Geografia. É possível observar a imagem de Hitler pendurada na parede ao fundo da sala. Era comum que os quadros do líder nazista estivessem por todas as escolas com a finalidade de reforçar para os alunos e professores quem era o líder deles.

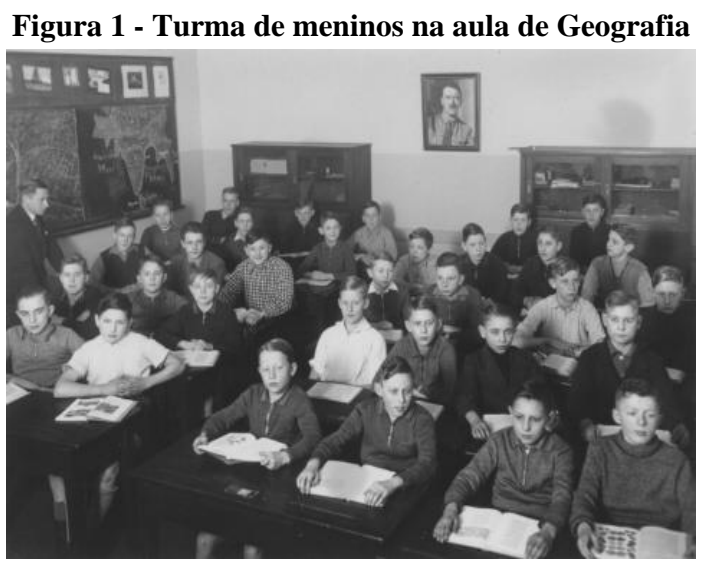

Fonte: United States Holocaust Memorial Museum (1933 - 1945)

\subsection{LÍNGUA ALEMÃ}

O ensino da língua alemã, como apresenta Koch (1973, p. 98) em seus relatos, "começou a ignorar os clássicos, em favor de um estudo da herança alemã e da comunidade alemã unida. A literatura era escolhida para ilustrar os laços que ligavam a comunidade na sua luta presente".

Tarefa difícil era ensinar a língua alemã, pois os professores tinham dificuldade para encontrar literatura para esse fim, o que ocasionou a utilização de livros de guerra escritos por nacionais-socialistas ou ainda a utilização de alguns livros clássicos desde que não tivessem sido escritos por alemães que professassem a fé judaica.

Nota-se em Bleuel (1972, p. 156) também, que para uma aula de linguagem exigia-se que o professor: "Em lugar da sincronização simplesmente contemplativa nos domínios da estética, dos conhecimentos históricos e dos temas críticos-científicos, inseria-se um comportamento valorizado e combativo, sempre predisposto ao trabalho e à criatividade".

As literaturas oferecidas para os alunos do ensino primário também foram adaptadas. Segundo Evans (2011), os livros traziam histórias que enalteciam Hitler e apresentavam os judeus sempre com aspecto "diabólico", escondidos em locais escuros, aguardando para fazer mal a uma criança alemã. Esse tipo de material era utilizado em sala de aula para o trabalho de leitura e interpretação dos pequenos. 


\subsection{CIÊNCIAS NATURAIS: BIOLOGIA}

Apesar de todas as disciplinas terem sido modificadas para contribuir com a disseminação da política racial, segundo relata Koch (1973, p. 99) eram nas aulas de Biologia que os professores podiam melhor transmitir o conteúdo ideológico racial na prática: "Nas ciências naturais, a Biologia foi a matéria que mais sofreu com os ensinamentos raciais. Teorias absurdas e não verificadas eram introduzidas nos compêndios com o fito de produzir um sentimento racial e um instinto racial na juventude alemã".

Bleuel (1972) destaca que as aulas de Biologia eram usadas justamente para demonstrar e anunciar a importância dos conhecimentos étnicos para a futura projeção do Reich. Os ensinamentos trabalhados nessa matéria foram totalmente manipulados para reforçar os ideais nazistas como o estudo das leis de hereditariedade, onde as crianças eram exaustivamente ensinadas sobre o valor da genética e a importância da origem de seus antepassados. Também eram nessas aulas que aprendiam sobre a seleção e aprimoramento das raças, reforçando claramente a importância da escolha certa do seu cônjuge a fim de que não ocorresse o problema da mistura racial. As crianças então aprendiam a apenas se relacionar com outros arianos, pois esses constituíam a raça pura.

Resume Evans (2011, p. 350) que "A biologia foi transformada para incluir as leis da hereditariedade, ensinamento racial, higiene racial, ensinamento sobre a família e política populacional".

\subsection{CIÊNCIAS RACIAIS E EUGENIA}

A disciplina de Ciências Raciais foi incorporada ao currículo escolar contribuindo para a compreensão dos alunos sobre a sua raça. Segundo Bartoletti (2006, p. 42), "as crianças ficavam sabendo que os arianos eram uma raça superior que iria dominar a Europa". E ainda nas aulas de Eugenia "aprendiam que os arianos só deviam se casar com outros arianos saudáveis. Não deviam misturar o sangue casando com não arianos" (BARTOLETTI, 2006, p. 42).

Era nas aulas dessas matérias que os educadores incutiam na mente dos alunos que esses pertenciam a uma Herrenrasse (raça superior) e que por isso deveriam dar ordem ao mundo utilizandose da força caso necessário, destacou Henry Metelmann, entrevistado por Bartoletti (2006).

Segundo Michaud (1996) ao admitirem que a ciência é racial e com isso condicionada pelo sangue, a Escola deveria acostumar o aluno a distinguir o que poderia ser útil à sua raça daquilo que poderia ameaçá-la.

\footnotetext{
Eram nas aulas de ciência racial que os alunos iniciavam-se realmente no que lhes era racialmente estranho. Embora os novos manuais de Rassenkunde ${ }^{7}$, assim como inúmeras brochuras, refletissem as múltiplas e contraditórias concepções que os ideólogos nazistas tinham das noções de povo, ou de nação, possuíam em comum incitar o próprio aluno a reconstruir o mito racial pela imagem e pelo texto (MICHAUD, 1996, p. 293).
}

Nessas aulas, eram aplicados exercícios para que os alunos treinassem o reconhecimento de outras "raças", conforme ensinadas pelos professores. De acordo com Michaud (1996), os alunos deveriam aprender a reconhecer a raça de alguém através da observação, para isso, analisavam personagens de poemas, novelas ou romances, retirando desses as conclusões sobre a raça e relacionando com os traços físicos que apresentavam. Posteriormente, o aluno era instruído a aplicar essa tarefa ao seu círculo pessoal, a fim de conseguir reconhecer os traços e comportamentos principalmente dos judeus,

\footnotetext{
${ }^{7}$ Rassenkunde - Ciência das Raças.
} 
observando assim a superioridade do ariano em relação ao judeu. Seguindo o aprendizado de identificação das raças:

\begin{abstract}
Visando exercitar o olhar da criança para julgar rostos estrangeiros, acrescentavam-se as sessões mais práticas ainda de mensuração da caixa craniana a que se entregavam mutuamente os alunos, nas salas de aula. Tratava-se de ora aprender a descrever a expressão frouxa e dissimulada de seus camaradas judeus, ora de aprender a reconhecer os mais belos espécimes da raça nórdica ou ariana (MICHAUD, 1996, p. 294).
\end{abstract}

Destaca ainda Michaud (1996) que para os nazistas a raça significa a alma e, por isso, a análise estava sempre vinculada ao físico e ao comportamento, pois poderia existir homens que apresentassem sinais reais de pertencimento à raça ariana, porém seriam considerados judeus por causa do "espírito". Sendo assim, o clima dentro dos lares e círculos de amizade passou a carregar um ar de tensão como se todos estivessem sendo observados e analisados e em qualquer sinal de simpatia pelos judeus já era suficiente para delatar a pessoa.

\title{
2.6 EXATAS: FÍSICA E MATEMÁTICA
}

Apesar de parecerem imparciais, até mesmo as disciplinas de física e matemática foram submetidas a reformulações para auxiliar no fortalecimento do sentimento de raça.

Reorientou-se a matéria de física para compreender em seus estudos, tópicos militares, tais como balística, aerodinâmica e radiocomunicação, conforme Evans (2011).

O ensino da matemática passou a utilizar conceitos do aspecto social a fim de reforçar a ideologia desejada. Koch (1973, p. 100) traz um exemplo claro dos exercícios cotidianos direcionados aos alunos:

\footnotetext{
Uma pessoa mentalmente incapaz custa 4 Reichsmark por dia, um aleijado custa 5,5 Reichsmark por dia e um criminoso condenado, 3,5 Reichsmark. As estimativas cautelosas dizem que dentro das fronteiras do Reich alemão 300.000 pessoas estão recebendo cuidados em instituições públicas. Quantos empréstimos matrimoniais de 1000 Reichsmark por casal poderiam ser concedidos anualmente, usando-se os fundos destinados a tais instituições?
}

Michaud (1996, p. 293) também apresenta outro exercício colocado para diversos estudantes: "Os judeus da Alemanha são de raça estrangeira. Em 1933, o Reich alemão contava 66060000 habitantes. Entre eles havia 499682 judeus praticantes. Qual porcentagem representavam?”.

Em complemento a isso, Evans (2011) relata que livros didáticos de aritmética básica começaram a ser utilizados a partir de 1935, pois se incluiu a aritmética social em seu conteúdo, instruindo um doutrinamento subliminar embutido também nos exercícios para as crianças resolverem. Por exemplo, uma das questões pedia para as crianças calcularem o quanto custaria ao Estado manter um doente mental vivo em um asilo. Esse tipo de exercício tornou-se cotidiano visando preparar a mente dos jovens para aceitar a ideologia vigente.

\subsection{ENSINO RELIGIOSO}

As aulas de ensino religioso foram suprimidas. Apesar de certa tentativa de coexistência por parte de alguns do Partido com as Igrejas cristãs, não foi sustentável a permanência dessa matéria.

Logo de início o clero já foi afastado do corpo docente das escolas, e o período que corresponderia ao ensino religioso foi preenchido por preleções sobre a doutrina nacional-socialista, como destaca Bleuel (1972). 
Barltoletti (2006) destaca também que não apenas em salas de aulas foi destituído o Ensino Religioso, mas a própria igreja católica perdeu poder por conta da atuação da Gestapo ${ }^{8}$ que perseguiu os padres, freiras e outros integrantes da igreja. Passaram a ordenar o tipo de sermão que os padres deveriam ministrar em suas missas e enquanto as escolas católicas ainda estavam em atuação, comandavam também o conteúdo a ser ensinado. Muitos padres foram presos e enviados aos campos de concentração por posicionarem-se contra o governo nazista.

\subsection{JUVENTUDE HITLERISTA}

Ao longo do governo do Terceiro Reich, o Partido Nazista, além de utilizar do sistema escolar regular para propagar a ideologia nazista, investiu em outras frentes que compunham o ensino obrigatório. Essas atividades que podem ser entendidas como extracurriculares, tornaram-se também obrigatórias para as crianças e jovens alemãs objetivando envolvê-los ainda mais profundamente nos projetos da nova Alemanha ambicionada por Hitler. Sendo assim, a juventude estava envolta em uma doutrinação constante que os direcionava na forma de pensar e agir. A principal Organização responsável por essas atividades extras é denominada Juventude Hitlerista. Na fotografia a seguir, vêse o líder nazista discursando para novos membros da Organização. Era costume de Hitler manter esse contato com a Juventude Hitlerista, pois se fazia lembrado para os jovens.

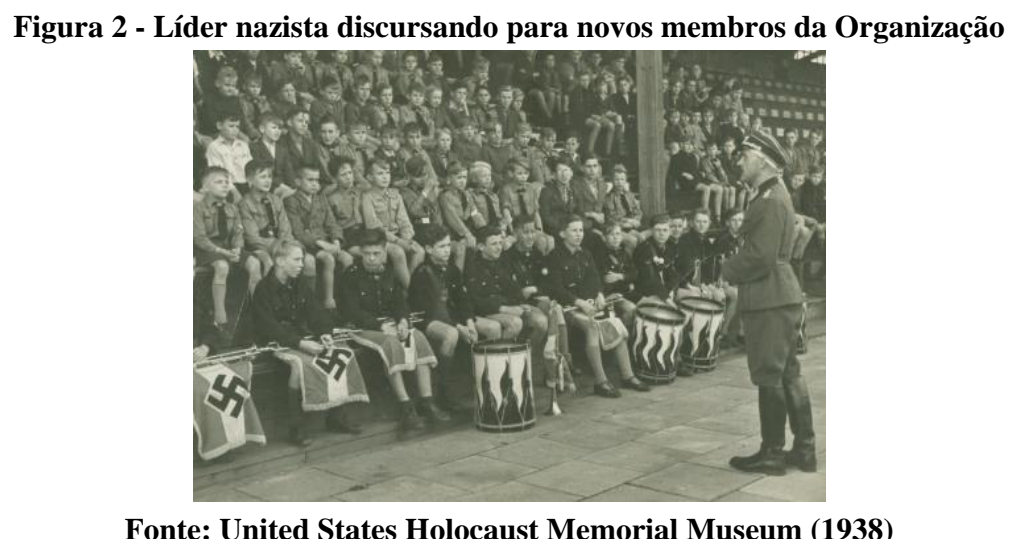

Levando em consideração a situação contextual da Alemanha antes da ascensão de Hitler, tendo como pontos críticos as altas taxas de desempregos, o governo fragilizado e a pobreza crescente, o nazismo se apresentou como a solução ideal para a futura geração do Reich. O Partido Nazista prometeu aos jovens alemães algo diferente do que estavam presenciando até o momento. Ao ingressarem na Organização denominada Juventude Hitlerista, esses jovens teriam um grande futuro em uma grande Alemanha. Conforme Bartoletti (2006, p. 13):

A Juventude Hitlerista oferecia a seus integrantes agitação, aventura e novos heróis para venerar. Deu a estes jovens esperança, poder e a oportunidade de fazer suas vozes serem ouvidas. Para alguns, deu também a oportunidade de se rebelarem contra os pais, professores, padres e outros superiores.

A Juventude Hitlerista foi formada oficialmente em 1926 antes de Hitler assumir o poder, tendo Kurt Gurber como líder e aproximadamente 6 mil integrantes, conforme destaca Bartoletti (2006). Em 1929 é declarado o grupo jovem oficial do Partido Nazista e em 1930 é fundada também a ala feminina

\footnotetext{
${ }^{8}$ Gestapo é o acrônimo em alemão de Geheime Staatspolizei, significando "polícia secreta do Estado".
} 
da JH - em alemão chamada, Bund Deutscher Mädel, aumentando o número de integrantes para 26 mil jovens. No ano de 1931 Baldur Von Schirach é indicado como novo líder da organização e já, em 1932, o número de participantes sobe para 99.586 jovens. Destaca Michaud (1996, p. 291) que para Schirach "Aquele que marcha nas fileiras da Hitler-Jugend não é um número entre milhões de outros, mas o soldado de uma ideia". Isso reforça o conceito de moldar esses jovens de acordo com o modelo idealizado pelo nacional-socialismo, pois esses "soldados de uma ideia" seriam então os responsáveis pelo futuro promissor da Alemanha.

$\mathrm{Na}$ imagem a seguir, pode-se observar jovens membros da JH fazendo a saudação nazista. Por dia, conforme Michaud (1996), uma pessoa fazia de 50 a 150 vezes essa saudação, sendo ela realizada com o braço direito erguido e bradada com convicção. A saudação hitlerista não representava apenas um ato automático de fidelidade ao Führer. Como revela Michaud (1996, p. 296): "A 'saudação alemã' significava não apenas a saudação do jovem alemão a Hitler, mas também sua saudação por Hitler, o "médico do povo alemão", o salvador da Alemanha cuja "visão" ou "ideia" do Reich eterno e puro um dia se tornaria realidade". Ao centro da imagem observam-se as meninas da BDM erguendo a bandeira do Partido.

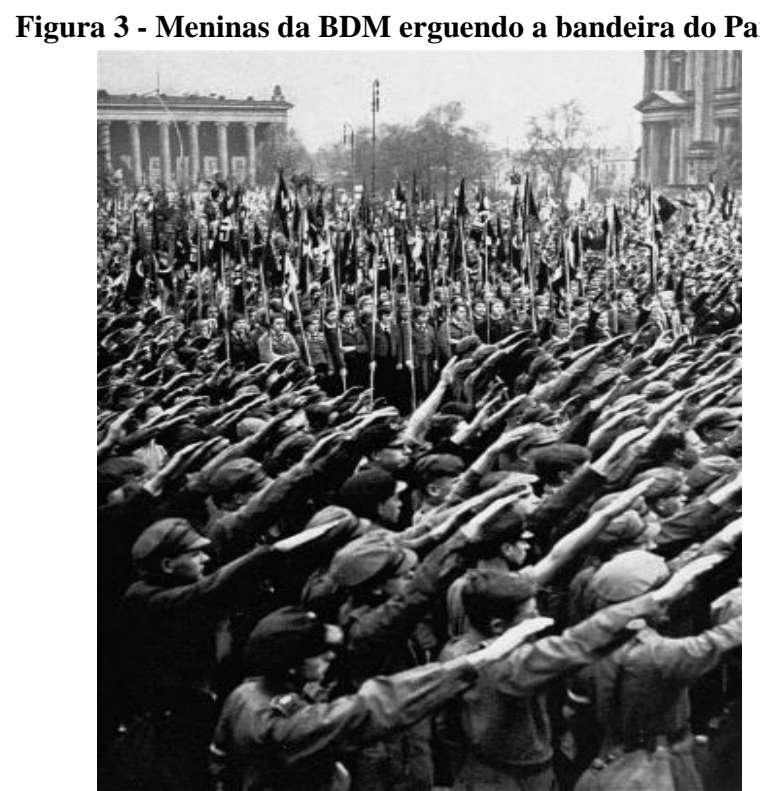

Fonte: United States Holocaust Memorial Museum (1933)

A JH esteve envolvida diretamente no processo de ascensão de Hitler, atuando nos boicotes às lojas e escritórios judeus e na queima de livros proibidos. Em 1936, através da Lei que tornou obrigatória a adesão de todos os jovens entre 10 e 18 anos na $\mathrm{JH}$, o número de integrantes dessa organização subiu para 5.437.602. Conforme Bleuel (1972) foi apenas em 1939 que os decretos dessa lei foram regulamentados de fato e com isso a não permissão dos pais à adesão dos filhos à organização da JH era sujeita à multa e intervenção da polícia local em caso de desobediência.

A Organização tornava-se cada vez mais atraente para as crianças e jovens, devido às atividades que lhes eram propostas, principalmente para aqueles de baixa renda que possivelmente jamais, em outra ocasião, teriam tais oportunidades. Conforme Evans (2011, p. 362):

A possibilidade de viagens de férias com a Juventude Hitlerista, as instalações esportivas e muito mais podiam tornar a organização atraente para crianças de famílias pobres da classe operária que antes não tinham oportunidade de desfrutar dessas coisas. Algumas podiam encontrar estímulo e um senso de valor pessoal na Juventude Hitlerista. 
Em 1940, Artur Axmann assume o cargo de líder principal da Juventude Hitlerista, que já ultrapassa em 7.287.470 o número de membros. Esses recebiam treinamento pesado, em que eram submetidos a uma rigorosa rotina. Conforme destaca Evans (2011, p. 364):

Os integrantes da Juventude Hitlerista eram treinados por camisas-pardas adultos, jogados em água gélida para se fortalecer, forçados a praticar exercícios cansativos no inverno sem vestimenta adequada, para desenvolver resistência física, e submetidos a punições cada vez mais brutais caso desobedecessem as ordens.

Essa Organização perdurou juntamente com seu Führer até o momento da rendição incondicional da Alemanha em 1945, marcando participação fundamental na Segunda Guerra. O próprio Hitler deixa seu interesse nos jovens claro, ao discursar em 1935 no Congresso do NSDAP em Nuremberg dizendo:

Nós começamos a educar este povo de uma maneira nova, a dar-lhe uma educação que se inicia com a juventude para jamais terminar. No futuro, o jovem homem passará de uma escola a outra. Isso começará pela criança para terminar com o velho combatente do movimento. Ninguém deve poder dizer que haverá para ele um tempo em que estará entregue a si próprio (BAYNES, N. H. 1942 apud MICHAUD, 1996. p. 297).

Para dar essa continuidade na educação e treinamento do jovem alemão, inicialmente constituiuse uma parceria entre a SA de Röhm ${ }^{9}$, onde, segundo Michaud (1996), os jovens da JH ficavam sob a tutela dos SA e ao completarem 18 anos passavam automaticamente para essa organização. Porém, a partir de 1934 essa parceria foi transferida para os SS de Himmler ${ }^{10}$, onde Schirach comprometia-se em educar os jovens para transformá-los em SS quando atingissem a idade.

A valorização dada a esse órgão do governo nazista era extremamente alta, pois era na juventude que consistia a força maior para as transformações no país. Aponta Koch (1973, p. 94):

Qualquer exame da estrutura de organização da JH mostrará que os assuntos a ela pertinentes eram considerados mais relevantes que qualquer outro da vida administrativa do país. O Ministério do Interior, o da 'Propaganda e Esclarecimento Publico', o Serviço do Trabalho e o exército, bem como as SS, estavam todos relativamente interessados nos assuntos juvenis.

Alguns conflitos são identificados devido à essa doutrinação extrema que os jovens vinham recebendo. Um desses conflitos é visto na casa paterna, pois muitos dos pais preocupavam-se com o nível do treinamento militar em que seus filhos estavam sendo submetidos e mais ainda com a doutrinação que lhes estava sendo imposta. A situação chegou a tal ponto que os pais não podiam mais confiar nos seus filhos, pois esses dificilmente hesitariam em delatar a própria família para a Gestapo, já que haviam sido convencidos pelo Partido que nada tinha maior importância do que agradar ao Führer. Segundo Bartoletti (2006, p. 78), "Muitos pais foram presos pela Gestapo, delatados pelos filhos". Um exemplo referido pela autora é o de Water Hess, que denunciou o pai por ter chamado Hitler de louco maníaco nazista, resultando no envio do pai para um campo de concentração no sul da Alemanha.

Existem ainda diversos outros relatos de crianças que, por terem os pais contrários à sua adesão à $\mathrm{JH}$, ameaçavam denunciá-los às autoridades se esses tentassem impedi-las de irem aos encontros. Vemos em Evans (2011, p. 367):

\footnotetext{
${ }^{9}$ Ernst Röhm , oficial alemão e co-fundador da Sturmabteilung (SA) (WILLIAMSON, 2008).

${ }^{10}$ Heinrich Luitpold Himmler, comandante militar da Schutzstaffel (SS) e um dos principais líderes do Partido Nazista (WILLIAMSON, 2008).
} 
Para os adolescentes, simplesmente era muito fácil irritar os pais ex-social-democratas saudando-os em casa com 'Heil Hitler!', em vez de 'bom dia'. 'Desse modo, a guerra é levada para dentro de cada família', observou a esposa de um antigo ativista do movimento operário. 'O pior', acrescentou ela, apreensiva, "é que você tem que se cuidar na frente dos próprios filhos".

Vale ressaltar que apesar da grande maioria das crianças e jovens devotar-se à JH, alguns, com o passar do tempo se desgastaram com o número de atividades e compromissos que era exigido. Como apresenta Evans (2011, p. 365) "Os adolescentes que já estavam trabalhando achavam as horas de treinamento particularmente cansativas. Acampar, outrora uma das atividades favoritas do movimento jovem, tornou-se cada vez mais impopular à medida que ficava mais militarizada."

\section{RESULTADOS E DISCUSSÕES}

Essas foram apenas algumas das modificações estabelecidas pelo Partido Nazista enquanto esteve no poder, mas que já proporcionaram um vislumbre do grau de doutrinação submetido às crianças e aos jovens alemãs. Observa-se então que diariamente aquela juventude foi sobrecarregada com essa ideologia que os colocava no centro do mundo, desmerecendo tudo ou quase tudo que não tivesse origem alemã. Submetidos a tal doutrinação, foram poucos os que conseguiram pensar e agir de outra forma que não a estabelecida pelo governo.

Pode-se ainda comentar sobre a consolidação desses ensinos na prática. Os membros da JH participaram ativamente de muitos momentos da Guerra, inclusive como soldados, embora nem todos tivessem a idade adequada. Lemos em Koch (1973, p. 138):

O governo usou plenamente o grande entusiasmo da Juventude Hitlerista. Durante toda guerra, membros da Jung-volk falsificaram repetidamente a certidão de nascimento para acrescentarem um ou dois anos, para serem aceitos, porque o pai ou o irmão haviam sido convocados e eles também 'queriam cumprir sua parte'. Normalmente se lhes permitia o ingresso.

A Juventude alemã, salvo algumas exceções, devotou-se inteiramente ao partido Nazista, tendo em seus corações o desejo de servir sua pátria não se importando de morrer por ela caso fosse necessário, como verifica-se neste relato:

Embora muitos alemães temessem mais uma guerra, a maioria da Juventude Hitlerista não tinha medo. Em 1939, os rapazes e moças estavam preparados para a guerra. - Eu estava pronto para lutar, matar e, se preciso, até morrer por meu Führer e minha pátria. Enquanto meus pais se preocupavam com as nuvens que ameaçavam guerra, eu acreditava no que aprendi na $\mathrm{JH}$ : que a guerra era um processo de limpeza necessário para a raça humana - contou Henry Melmann (BARTOLETTI, 2006. p. 69).

Segundo Bartoletti (2006), a ala feminina da JH, durante a invasão da Polônia auxiliou na acomodação das famílias alemãs em suas novas casas. Essas meninas sentiam-se úteis com tal atividade, pois acreditavam estar servindo sua pátria. As garotas iam de uma aldeia a outra a fim de ajudar novas famílias alemãs a se instalarem. Por devoção à pátria elas cozinhavam, limpavam e remendavam roupas para as famílias e cuidavam também dos bebês e dos doentes.

A doutrinação que as moças receberam foi tão forte ao ponto de não se darem conta, ou não quererem se dar conta, do fato que as famílias que estavam sendo retiradas de suas casas para os alemães ocuparem, eram enviadas a campos de concentração (chamados de campos de custódia para disfarçar sua finalidade) acreditando serem locais para proteção dos judeus conforme Bartoletti (2006). 
Os meninos da JH também estiveram bastante envolvidos na Guerra. Durante os ataques dos Aliados, estes "ajudavam os civis a esconderem-se nas casamatas subterrâneas, onde cuidavam das crianças distribuindo comida e brinquedos" (BARTOLETTI, 2006, p. 81). Tarefa desgastante, mas que ficaria ainda pior com o decorrer da Guerra. Passando os meses, a situação ia se agravando e as obrigações da Juventude Hitlerista foram tornando-se cada vez mais perigosas, chegando ao ponto em 1943, segundo Bartoletti (2006), de ser ordenado que todos os meninos a partir de 15 anos deveriam comandar baterias antiaéreas. Foram convocados também para cavar trincheiras antitanques para impedir a entrada dos tanques inimigos no território, o que lhes custavam horas e horas de trabalho pesado cavando.

Após as perdas da Rússia, Hitler viu que precisaria ampliar o contingente alemão, então conforme visto em Bartoletti (2006), a partir de 1943 criou uma nova divisão de elite da Unidade da Morte-SS denominada Juventude Hitlerista-SS. Essa era formada por integrantes da JH que eram enviados a um campo de treinamento rápido para tão logo serem designados para frente de batalha. A Juventude Hitlerista-SS participou de muitos combates e enfrentamentos sempre confiantes de estarem cumprindo seu dever, conforme haviam sido ensinados. Como observado em um dos casos relatados por Bartoletti (2006, p. 57), "ele acreditava no que a educação nazista tinha lhe ensinado: que o líder tem sempre razão e que os judeus eram inimigos da Alemanha", falando aqui sobre Afons Heck, membro ativo da JH.

Mesmo após a rendição da Alemanha, em 1945, levaria ainda muitos anos para que os integrantes da JH de fato assimilassem a verdade sobre o partido nazista, e principalmente sobre sua participação no grande número de assassinatos em massa ocorridos durante o governo do Terceiro Reich. Inicialmente muitos membros da $\mathrm{JH}$ não acreditaram no que os Aliados contavam sobre o nazismo, como ressalta Bartoletti (2006). Esses achavam que as imagens, filmes e relatos que eram obrigados a assistir haviam sido montados pelos Aliados para difamar os nazistas. Levou algum tempo para muitos desses jovens superarem a doutrinação nazista e perceberem as consequências de seus atos.

Contudo, sabe-se que os jovens membros da JH não foram julgados no Tribunal de Nuremberg. Bartoletti (2006, p. 136) destaca que o Tribunal concluiu "que as crianças e adolescentes do Terceiro Reich foram traídas, desertadas e sacrificadas por um partido e um regime que as usou para chegar ao poder". Alguns integrantes mais atuantes na Organização foram julgados em tribunais populares, onde foi decidido que deveriam passar por uma "desnazificação" mais profunda para que jamais os ideais nazistas voltassem ao poder na Alemanha.

Para superar a ideologia nazista no país seria necessária uma reeducação, depois de tantos anos de propaganda e doutrinação nazista. Para isso, as qualidades da democracia e as liberdades civis foram restituídas, pelo menos na parte Ocidental da Alemanha que estava sob a tutela dos Estados Unidos, França e Inglaterra. Segundo Bartoletti (2006, p. 142): "Professores receberam novo treinamento. Os livros nazistas foram jogados fora e o currículo escolar foi reformado. Os professores foram incentivados a promover a visão independente e o pensamento crítico de todos os assuntos e a ensinar o aluno a pensar com a própria cabeça".

Um longo caminho foi percorrido para a reestruturação da Alemanha após longos anos de doutrinação enraizada em uma visão racista de mundo. Atualmente, a educação na Alemanha incentiva essa visão independente não exigindo homogeneidade de pensamento, o que proporcionou grande crescimento para toda nação. Ainda assim, as marcas deixadas pelo Terceiro Reich estarão sempre presentes na memória de quem presenciou ou mesmo apenas estudou o período em questão. 


\section{CONSIDERAÇÕES FINAIS}

A análise das obras utilizadas, bem como o complemento da revisão bibliográfica referido, contribuiu para uma reflexão sobre um dos métodos utilizados pelo governo do Terceiro Reich para transmitir sua ideologia e doutrinar os mais jovens da nação, que foram a educação escolar e as atividades extracurriculares proporcionadas pelo governo para esse fim.

Ao analisar o contexto no qual estava inserida a Alemanha, após o término da Primeira Guerra, assim como as condições que levaram a nação a retomar o conflito com a ascensão de Adolf Hitler. Então, pode-se perceber que para grande parte da população, Hitler surgiu como um salvador que emergia para solucionar os problemas e as crises pelos quais a Alemanha estava passando. Hitler apresentou o nacional socialismo como a solução para a crise vigente e, por isso, é possível perceber o que moveu os alemães a acreditarem nas promessas nazistas.

Pensando também sobre as transformações estabelecidas no currículo escolar e nas suas disciplinas, pode-se compreender que, segundo as fontes, nenhuma delas ficou de fora do processo de "nazificação", pois em todas as matérias ensinadas na escola regular a ideologia nazista se fazia presente. Como observado anteriormente, nem mesmo as disciplinas das Ciências Exatas, como a Física e a Matemática, deixaram de propagar o pensamento nazista, visto que a construção das questões e exercícios destinados aos alunos eram planejados de forma a carregar essa ideologia.

A preocupação com a doutrinação da juventude não ficou restrita apenas ao ambiente escolar regular, mas estendeu-se aos demais ambientes frequentados pelos alunos, como a Juventude Hitlerista. A JH, referida neste artigo, desempenhou um papel fundamental nessa continuidade da modulação dos jovens nos princípios ambicionados por Hitler. Sendo assim, a obrigatoriedade de ingressar na JH deixou pouca margem para os jovens que desejavam pensar e agir diferente. As crianças e os jovens de forma geral foram diariamente submetidas a tamanha doutrinação que seria difícil esperar que não seguissem Hitler, pois suas opções eram restritas.

Creio ser válido destacar que apesar da forte manipulação e doutrinação que sofreu a juventude alemã, houve quem resistisse e tentasse transformar a situação. Seria tema para outro trabalho, mas apenas gostaria de mencionar sobre dois personagens que Susan Campbell Bartoletti relatou em seu estudo e que apesar de estarem envoltos nessa doutrinação, resistiram e buscaram mudanças, mesmo que lhes custando a vida.

Hans Scholl e Sophie Scholl, dois dos irmãos da família Scholl, fizeram parte do grupo denominado Rosa Branca e foram responsáveis por distribuir um grande número de panfletos questionando a ideologia nazista na Universidade de Munique, onde estudavam, bem como por toda cidade. Fizeram isso durante algum tempo até serem vistos em ação por um membro fiel do partido nazista que os delatou. As suas ações lhes custaram suas vidas. Ambos foram mortos, juntamente com vários outros membros do grupo, mas a lembrança da coragem que demonstraram serviu de referência para que a Alemanha refletisse sobre o passado recente. Destaque interessante traz Bartoletti (2006, p. 147), ao informar que a praça principal da Universidade de Munique foi nomeada "Praça Irmãos Scholl" em homenagem a eles.

Outros grupos também se organizaram para resistir ao sistema, alguns com pouco alcance, mas provando que ainda haviam jovens com mentes fortes dispostos a lutar contra a doutrinação.

Finalmente, este estudo torna-se relevante, pois através dele é possível analisar o quão significativo foi o controle do nacional-socialismo sobre a população, uma vez que o sistema de conceitos nazista era transmitido desde a infância no ambiente escolar. Não se restringindo apenas a ele, 
mas estendendo-se ao dia a dia das crianças, jovens e também adultos. A educação foi utilizada como um meio para a imposição de uma ideologia estabelecida pelos governantes.

Para quem ocupa o papel de educador ou qualquer outro cargo que represente influência sobre outras pessoas é válida a reflexão sobre esse acontecimento, pois a geração de crianças e jovens que seguiu o nazismo não nasceu odiando e imbuída do sentimento de superioridade. Esses foram ensinados a pensar dessa forma por aqueles que exerciam poder sobre elas. Devido à isso, todos aqueles que exercem alguma posição de autoridade na sociedade devem buscar uma conduta ética, proporcionando liberdade de pensamento, não limitando os que estão sob sua responsabilidade a seguir um conceito cegamente sem pensar a respeito.

\section{REFERÊNCIAS}

ARENDT, Hannah. Origens do totalitarismo. Tradução de Roberto Raposo. São Paulo: Companhia das Letras, 1989.

BARTOLETTI, Susan Campbell. A juventude hitlerista: a história dos meninos e meninas nazistas e a dos que resistiram. Tradução de Beatriz Horta. Rio de Janeiro: Relume Dumará, 2006.

BLEUEL, Hans Peter. O sexo na Alemanha Nazista. Tradução de Theobaldo de Souza. Rio de Janeiro: Senegra, 1972.

BRANDT, Cleri Aparecida. A educação na Alemanha nazista e seu papel na modulação de ideias e comportamentos. Historia de la educación, Buenos Aires. v 14, n 2. 2013. Disponível em: <http://ppct.caicyt.gov.ar/index.php/anuario/article/view/2840>. Acesso em: 3 out. 2015.

CAETANO, Tiago Lemanczuk Fraga. Mein Kempf e o ideário nazista. Consilium - Revista Eletrônica de Direito, Brasília, DF, v. 1, n. 4, maio/ago. 2010. Disponível em: $\langle$ http://www.unieuro.edu.br/sitenovo/revistas/downloads/consilium_04_01.pdf >. Acesso em: 5 mar. 2016.

CHEVALLIER, Jean-Jacques. As grandes obras políticas de Maquiavel a nossos dias. Tradução, Lydia Cristina. 8. ed, Rio de Janeiro: Agir, 2001. Livro eletrônico versão em PDF.

EVANS, Richard J. O Terceiro Reich no poder. Tradução de Lúcia Brito. 1. ed, São Paulo: Planeta do Brasil, 2011. Livro eletrônico versão em PDF.

HANNOUN, Hubert. O nazismo: Educação? Domesticação... Fundamentos Ideológicos da formação nazi. Tradução de Fátima e Carlos Gaspar. Lisboa: Instituto Piaget, 1997.

HITLER, Adolf. Minha luta: Mein Kampf. São Paulo: Editora Moraes, 1983.

KARNAL, Leandro. Conversas com um jovem professor. São Paulo: Contexto, 2016.

KLEMPERER, Victor. LTI: A linguagem do Terceiro Reich. Tradução de Miriam Bettina Paulina Oelsner. Rio de Janeiro: Contraponto, 2009.

KLEMPERER, Victor. Os diários de Victor Klemperer: testemunho clandestino de um judeu na Alemanha nazista, 1993-1945. Tradução de Irene Aron. São Paulo: Companhia das Letras, 1999.

KOCH, H. W. A juventude hitlerista: Mocidade traída. Tradução de Edmond Jorge. Rio de Janeiro: Ed. Renes, 1973.

LENHARO, Alcir. Nazismo, o triunfo da vontade. São Paulo: Editora Ática, 1986. 
MICHAUD, Eric. "Soldados de uma idéia" Os jovens do terceiro Reich. In: LEVI, Giovanni; SCHMITT, Jean-Claude (Org.). História dos Jovens 2 - A época contemporânea. Tradução de Paulo Neves, Nilson Mulin, Maria Lúcia Machado. São Paulo: Companhia das Letras, 1996. p. 291317.

PERRONE-MOISÉS, Claudia. Centro de estudos Hannah Arendt. São Paulo, 2013. Disponível em: <https://hannaharendt.wordpress.com/2013/05/23/cem-anos-de-hannah-arendt/>. Acesso em: 10 maio. 2016.

PERRY, Marvin et al. Civilização Ocidental. Uma História concisa. São Paulo: Martins Fontes Editora LTDA, 1985.

SHIRER, William L. Ascensão e queda do Terceiro Reich, volume I: triunfo e consolidação (1933 1939); Tradução de Pedro Pomar. Rio de Janeiro: Agir, 2008.

UNITED STATES HOLOCAUST MEMORIAL MUSEUM. [Foto \#47464]. Hamburg, 1933 - 1945. Disponível em:

<http://digitalassets.ushmm.org/photoarchives/detail.aspx ?id=1134260\&search=hitler+school\&index= 8>. Acesso em: 25 maio. 2016.

UNITED STATES HOLOCAUST MEMORIAL MUSEUM. [Foto \#57714]. Krakow, [Krakow] Poland, 1938. Disponível em:

<http://digitalassets.ushmm.org/photoarchives/detail.aspx?id=1142860\&search=hitler+youth\&index= 3>. Acesso em: 25 maio. 2016.

UNITED STATES HOLOCAUST MEMORIAL MUSEUM. [Foto \#83958]. Germany , May 1, 1933. Disponível em:

<http://digitalassets.ushmm.org/photoarchives/detail.aspx?id=14022\&search=hitler+youth\&index=7>. Acesso em: 25 maio. 2016.

VITKINE, Antoine. Mein Kampf: A história do livro. Rio de Janeiro: Nova Fronteira, 2010.

WILLIAMSON, Gordon. O instrumento de terror de Hitler. Tradução de Roberson Melo. São Paulo: Escala, 2008. v. único. 